\title{
ESTUDOS E PRÁTICAS DOCENTES EM EDUCAÇÃO POPULAR: NARRATIVAS DE UM COTIDIANO DE COMPLEXIDADES SAÚDE-DOENÇA
}

\author{
STUDIES AND TEACHING PRACTICES IN POPULAR EDUCATION: NARRATIVES OF A DAILY ROUTINE OF \\ HEALTH-DISEASE COMPLEXITIES
}

\section{ESTUDIOS Y PRÁCTICAS DOCENTES EN EDUCACIÓN POPULAR: NARRACIONES DE UNA RUTINA DIARIA DE} COMPLEJIDADES SALUD-ENFERMEDAD

\author{
Wany Marcele Costa Góes Dias ${ }^{1}$ \\ Ivanilde Apoluceno de Oliveira ${ }^{2}$
}

\begin{abstract}
Resumo: Neste artigo, apresentamos o contexto socioeducacional e cultural em um ambiente hospitalar expresso por seus atores como práxis de formação docente mediante a complexidade saúde-doença. As ações educativas são desenvolvidas por um Núcleo de Educação Popular, em um hospital de Belém com jovens e adultos, em sua maioria, mulheres vítimas de escalpelamento. 0 foco é para os impactos da experiência docente em ambiente hospitalar na formação de professores comprometidos com a inclusão social por meio da educação em espaços não convencionais de ensino. Trata-se de dados parciais de uma pesquisa, em que foi utilizada a técnica da história de vida, dinâmicas pedagógicas, por meio de falas, expressões corporais e desenhos, levantamento bibliográfico sobre temáticas relacionadas ao objeto de estudo e a observação participante. Para sistematização e análise dos dados foram utilizadas técnicas da análise de conteúdo. Os dados apontam que as dimensões do cotidiano no ambiente hospitalar atrelada a experiência educativa favorecem a formação docente inclusiva
\end{abstract}

Palavras-chave: Ambiente Hospitalar. Cotidiano. Educação Popular. Formação Docente. Inclusão social.

\begin{abstract}
In this article, we present the socio-educational and cultural context in a hospital environment expressed by its actors as teacher training praxis based on the health-disease complexity. Educational activities are carried out by a Popular Education Center, in a hospital in Belém with young people and adults, mostly women victims of scalping. The focus is on the impacts of teaching experience in a hospital setting on
\end{abstract}

\footnotetext{
${ }^{1}$ Universidade do Estado do Pará. Belém, Pará, Brasil.

${ }^{2}$ Universidade do Estado do Pará. Belém, Pará, Brasil.
} 
the training of teachers committed to social inclusion through education in unconventional teaching spaces. These are partial data from a research, in which the technique of life history, pedagogical dynamics was used, through speeches, body expressions and drawings, bibliographical survey on themes related to the object of study and participant observation. To systematize and analyze the data, content analysis techniques were used. The data indicate that the dimensions of everyday life in the hospital environment linked to the educational experience favor inclusive teacher education.

Keywords: Hospital Environment. Daily. Popular Education. Teacher Education. Social inclusion.

Resumen: En este artículo, presentamos el contexto socioeducativo y cultural en un entorno hospitalario expresado por sus actores como una práctica de formación docente a través de la complejidad de la enfermedad de la salud. Las actividades educativas son llevadas a cabo por un Centro de Educación Popular, en un hospital de Belém con jóvenes y adultos, en su mayoría mujeres víctimas del cuero cabelludo. La atención se centra en los impactos de la experiencia docente en un entorno hospitalario en la formación de docentes comprometidos con la inclusión social a través de la educación en espacios de enseñanza no convencionales. Estos son datos parciales de una investigación, en la que se utilizó la técnica de la historia de la vida, la dinámica pedagógica, a través de discursos, expresiones corporales y dibujos, encuestas bibliográficas sobre temas relacionados con el objeto de estudio y observación participante. Para sistematizar y analizar los datos, se utilizaron técnicas de análisis de contenido. Los datos indican que las dimensiones de la vida cotidiana en el entorno hospitalario vinculadas a la experiencia educativa favorecen la formación inclusiva del profesorado.

Palabras clave: Ambiente hospitalario. Todos los dias Educación popular. Formación del profesorado. Inclusión social.

\section{INTRODUÇÃO}

Neste texto, convidamos o leitor a adentrar no contexto socioeducacional e cultural de um ambiente hospitalar expresso, por seus atores, como práxis de formação docente mediante a complexidade saúde-doença e exclusão-educação-inclusão. As ações educativas são desenvolvidas por um Núcleo de Educação Popular, em um hospital de Belém do Pará, com jovens e adultos, em sua maioria, mulheres vítimas de escalpelamento. O foco é para os impactos da experiência docente em ambiente hospitalar na formação de professores comprometidos com a inclusão social por meio da Educação Popular em espaços não convencionais de ensino.

Direcionamos este estudo a uma (01) das mulheres vítimas de escalpelamento, educanda, e a duas (02) educadoras que desenvolvem suas ações educativas pelo Núcleo. Neste estudo, a educanda-paciente foi denominada pelo nome fictício Rosa e as educadoras foram denominadas Carmem e Carina.

Apresentamos dados parciais da pesquisa de campo, tendo como estudo as dimensões socioeducacionais e culturais cotidianas de um ambiente hospitalar a partir da experiência educativa desenvolvida por um Núcleo. 
O Núcleo desenvolve ações interligadas de ensino, pesquisa e extensão, centradas em torno de um eixo comum, a Educação Popular na perspectiva Freireana, contando também com a contribuição de outras abordagens teóricas no âmbito sociohistórico, sociointeracionista e multicultural crítico. A pesquisa foi aprovada pelo Comitê de Ética do hospital, cumprindo-se os cuidados éticos necessários ao desenvolvimento da pesquisa em ambiente hospitalar. Consiste em uma pesquisa de campo, de abordagem qualitativa, na qual foram utilizadas as técnicas da história de vida e dinâmicas pedagógicas. A pesquisa qualitativa, à luz do enfoque dialético, segundo Minayo (1993), volta-se para o caráter de totalidade da existência humana.

Para estabelecermos uma relação próxima com os sujeitos da pesquisa realizamos a observação participante. Trata-se de uma técnica de produção de dados que tem como elemento norteador o diálogo mediante a construção de uma relação de confiança entre os sujeitos da pesquisa, capaz de fornecer não somente as informações necessárias ao atendimento da questãoproblema pesquisada, mas de favorecer o estabelecimento de uma relação humana pautada em pressupostos éticos.

A observação participante é uma "tentativa de colocar o observador e o observado do mesmo lado, tornando-se o observador um membro do grupo de molde a vivenciar o que eles vivenciam e trabalhar dentro do sistema de referência deles" (MANN,1970 apud LAKATOS, 2007, p.91). Com as educadoras adotou-se a observação dos encontros educativos; levantamento documental dos relatórios diários dos educadores do Núcleo e das produções dos educandos e entrevista com a utilização de roteiro semiestruturado.

Com a educanda-paciente foi utilizada entrevista aberta com a técnica da história de vida, pois a mesma favorece uma visão processual das fases da sua vida, tendo como alicerces a fidelidade das experiências e interpretações de cada ator sobre suas vivências. Segundo Haguette (1987), na abordagem metodológica biográfica, situa-se a técnica história de vida que pode ser utilizada como procedimento de produção de dados e tem como principal característica uma relação de proximidade entre pesquisador e pesquisado.

A maioria das pessoas atendidas no ambiente hospitalar pesquisado é constituída por mulheres que participam de Programas como "Mãe Canguru" e "Mãe Coruja" e as vítimas de

\footnotetext{
${ }^{3} \mathrm{O}$ programa Mãe Canguru atende recém-nascidos prematuros, que ficam em contato permanente e direto com o corpo da mãe. O método acelera a recuperação das crianças e reduz o tempo de permanência no hospital.

${ }^{4} \mathrm{O}$ alojamento da Mãe Coruja destina-se às mães de bebês internados.
} 
escalpelamento. As mulheres de áreas ribeirinhas, por usarem cabelos longos, são as mais atingidas em acidentes de escalpelamento em barcos na Amazônia.

Ribeiro (2009, p. 34-35) explica que:

durante as travessias de barco, os ribeirinhos têm de lidar com algumas situações perigosas como, por exemplo, a entrada de água pelo espaço que fica entre o motor e o eixo ${ }^{5}$. A aproximação da água do eixo do motor, somado a um pequeno descuido, pode provocar o escalpelamento, pois a força centrípeta gerada pelo eixo em rotação atrai os cabelos da vítima, fazendo com que o couro cabeludo seja bruscamente arrancado.

A necessidade de tratamento médico obriga essas mulheres a interromperem tanto a educação escolar quanto as práticas sociais cotidianas de sua comunidade; deslocarem-se de seu local de origem para entrarem em contato com a realidade dos grandes centros urbanos, incluindo, o hospitalar.

No espaço educacional hospitalar em que o Núcleo atua, essas mulheres estabelecem suas relações interpessoais que vão fazendo parte de um cotidiano repleto de significações sobre a condição da mulher na sociedade, principalmente, em torno do ser mãe, ser filha e das relações com a estética, devido às mutilações corporais provocadas pelo acidente de escalpelamento. Condições que se encontram em um contexto de exclusão social que se estabelece nas referências de gênero, estética, etnia e classe social.

O ambiente hospitalar em que as mulheres em tratamento de saúde e seus acompanhantes realizam atividades educacionais constitui-se em uma comunidade hospitalar, caracterizada pela diversidade cultural. Para Fleuri (2006) a diversidade cultural é baseada no estabelecimento de conteúdos e costumes culturais pré-dados e pela dinâmica da diferença como um processo de significação e afirmação da cultura em meio à produção de campos de força que categorizam e discriminam comportamentos, saberes e práticas sociais.

\section{BASES CONCEITUAIS DO ESTUDO: AS DIMENSÕES DO COTIDIANO E DA EDUCAÇÃO POPULAR NA FORMAÇÃO DOCENTE INCLUSIVA}

A vida cotidiana apresenta-se como um nível da "totalidade" e como tal não é um campo fechado, pois está ligado a outros níveis da realidade social como o econômico, o biológico, o psicológico, etc.

\footnotetext{
${ }^{5}$ Essa água é geralmente retirada manualmente pelas crianças ou mulheres, utilizando uma cuia (objeto artesanal, feito de um fruto local).
} 
Portanto, é no nível da vida cotidiana que emergem as grandes ações e criações e é nesse nível que essas são postas em prática configurando um constante movimento criativo a práxis. Assim, "as criações devem vir à vida cotidiana para verificar e confirmar a validade da criação" (PENIN, 1989, p.17).

Portanto, a vivência é um elemento fundante da prática cotidiana e é a partir da vivência, compreendida enquanto experiência sensível, que se abrem as reais possibilidades de conhecimento do cotidiano, significando buscar ir além das questões instituídas sobre a sociedade, sobre o saber e comportamento social, mas uma mudança de perspectiva.

Significa saber distinguir, antes, aquilo que vem de baixo, a socialidade enquanto nasce, com a carga de afeto que lhe é inerente, do que as formas econômicopolíticas das quais até então, se pensou que determinassem (ou sobredeterminassem) toda a vida social (MAFFESOLI, 1998, p.177).

Dessa forma, o cotidiano é compreendido como acontecimento, o qual é determinado por fatores objetivos e subjetivos, por um conjunto de significações que em sua dinamicidade tem ao mesmo tempo dimensão efêmera e perdurável. Nessa dinâmica, o passado se encontra no presente, não de forma determinante, mas atual. É assim que no cotidiano "aquilo que é sempre e renovadamente antigo é, igualmente, sempre e renovadamente atual" (MAFFESOLI, 1998, p.178).

Neste contexto, a Educação Popular adentra no cotidiano sociocultural dos espaços não convencionais de ensino como movimento social de ruptura com as práticas pedagógicas tradicionais. Inserese como movimento de contestação do estabelecimento das relações humanas discriminatórias e excludentes e tem na reflexão-ação-reflexão sobre as condições concretas de vida do sujeito no mundo e com o mundo o favorecimento de práticas de solidariedades e de respeito à vida. Vida humana que é entendida como "condição de possibilidade para a ação e para a reflexão sobre a ação" (DUSSEL 2000 apud OLIVEIRA, 2005, p.104). Freire (1987, p.81) indica que:

a educação como prática de liberdade, ao contrário daquela que é prática da dominação, implica a negação do homem abstrato, isolado, solto, desligado do mundo, assim também a negação do mundo como uma realidade ausente dos homens.

Assim, a Educação Popular se configura como movimento social educacional que mobiliza estudos e práticas compromissadas com as classes populares, visando sua instrumentalização ética e política por meio do favorecimento da ampliação do conhecimento crítico reflexivo, objetivando a ruptura com as condições de opressão e de negações sociais vivenciadas pelas populações marginalizadas das condições básicas de educação, moradia e saúde (BRANDÃO, 2002). 
Educação que se situa no movimento de busca do ser-mais, se alicerça sob a ótica da formação do sujeito compreendido como ser de reflexão-ação-reflexão, inconcluso, indeterminado. "Desta maneira, a educação se re-faz constantemente na práxis. Para ser tem que estar sendo" (FREIRE, 1987, p.84).

De acordo com Gazzinelli (2006), as práticas educativas voltadas para o contexto do tratamento de saúde evidenciam os efeitos dos movimentos sociais que visam à humanização dos espaços hospitalares, tendo se iniciado no Brasil durante a segunda metade do século $X X$, no sentido de minimizar as tensões cotidianas causadas pelas enfermidades e o desgastante tratamento médico hospitalar.

Nessa compreensão, saúde e doença estão em constante relação com as manifestações biológicas e sociais (MINAYO, 1999). O olhar voltado para a pessoa em tratamento de saúde não mais se limita ao tratamento físico de um corpo, mas evidencia um sujeito constituído de uma história de vida, constituinte de uma cultura e de interação social contínua.

Nesse contexto, a educação popular em ambiente hospitalar emerge como prática de inclusão social, crítica, dialógica e democrática, que na valorização das experiências vividas pelos sujeitos da comunidade hospitalar e no favorecimento da ampliação do conhecimento, propicia a construção de novas formas de representar-se no mundo e com o mundo. Condições que são possibilitadas por meio da práxis educativa libertadora, que tem nas diretrizes educacionais freireanas elementos ético-políticos que permitem a consolidação da transformação de realidades excludentes.

A educação dialógica tem na liberdade dos sujeitos de dizerem a sua fala a condição existencial e política de expressão humana das suas posições no mundo, por meio da comunicação que não se esgota na relação eu-tu e possibilita afirmar que "ninguém pode dizer a palavra verdadeira, sozinho ou dizê-la para os outros, num ato de prescrição, com o qual rouba a palavra aos demais" (FREIRE, 1987, p.91). Desta forma, com vistas à transformação social, passa a ser importante o diálogo que pautado na liberdade de expressão os sujeitos, envolvam os educandos no processo educativo (SOARES; MOREIRA; BENTES; 2019).

Na práxis educativa do Núcleo, temos:

- o diálogo nas dimensões metodológica, política e existencial permite a comunicação entre os sujeitos do conhecimento, o direito de todos de dizerem a sua fala, a interação entre os saberes, a plena realização da condição humana, a problematização coletiva das situações existenciais e sociais, e outras.

- a oralidade apresenta-se como fonte de expressão do ser humano sobre o seu existir, o seu saber experienciado e a sua cultura. $O$ educando tem que ser estimulado a falar e expressar sua visão de mundo, rompendo com a cultura do silêncio e o autoritarismo da relação tradicional professor/aluno (NEP, 2008). 
As pessoas atendidas na Educação de Jovens e Adultos apresentam, segundo Oliveira (2004, p.1-2), três especificidades: a etária, caracterizada pela (não-infância), pessoas que não tiveram acesso ou foram excluídas do processo educativo escolar na chamada idade escolar (dos 07 aos 14 anos), "Não são crianças, mas pessoas jovens, adultas e idosas com experiência de vida e Profissional"; a especificidade sociocultural, "Jovens, adultos e idosos «marginalizados» pelo sistema econômico-social, vistos como "analfabetos» e muitas vezes considerados «incapazes de aprender»"; e a especificidade éticopolítica, "porque está no centro da relação de poder existente entre os escolarizados e não escolarizados, entre os alfabetizados e os nãoalfabetizados". Diante dessas especificidades, considera-se o educador sob a perspectiva proposta pelo Núcleo segundo Oliveira (2002, p.21-22):

- Responsável pelo desenvolvimento da ação pedagógica, cabendo-lhe o papel de orientar, de pensar junto, de propor caminhos para a instrumentalização do saber escolar, existindo uma intencionalidade, éticopolítica no ato educativo que não pode deixar de ser considerada por ele;

- Capaz de assumir o compromisso político com as classes populares, respeitando o seu direito de "dizer a sua palavra" e de ser, também, sujeito do conhecimento, compreendendo a sua situação social e trabalhando junto com ele para a superação da exclusão pessoal e social a que o jovem e adulto esta sujeito;

- Capaz de instrumentalizar-se teoricamente para um reflexão permanente sobre a sua prática docente, buscando construir uma nova práxis pedagógica frente à pratica instituída, desassimilando hábitos adquiridos; - Compreender que a realidade socioeducacional é dialética, conflituosa, processual e dinâmica e o seu papel político é de problematizála, na busca conjunta com os (as) alunos (as) de desvelá-la e transformá-la;

- Interagir com a comunidade buscando integrar escola e comunidade numa ação educativa popular.

A formação do educador, neste contexto, segundo Tardif e Gauthier (1996) tem papel fundamental nas experiências cotidianas e na prática docente. E, no cotidiano do ambiente hospitalar saberes e práticas docentes se articulam como práxis de formação dos atores-: educador-educando.

Constitui, portanto, um processo dialético de formação profissional temporal, heterogêneo e em constante aperfeiçoamento, fazendo com que:

um professor de profissão não seja somente alguém que aplica conhecimentos produzidos por outros, não é somente um agente determinado por agentes sociais: é um ator no sentido forte do termo, isto é, um sujeito que assume sua prática a partir dos significados que ele mesmo lhe dá, um sujeito que possui conhecimentos e um saber-fazer provenientes de sua própria atividade e a partir dos quais ele a estrutura e a orienta (TARDIF, 2004, p.230). 
Assim, formação do educador popular tem como ponto de partida a humanização das relações entre sujeitos e saberes, democratização dos espaços e formas de ensinar e aprender, comprometimento éticopolítico com as populações atingidas por negações sociais como educação e saúde. Neste sentido, "A questão da formação docente ao lado da reflexão sobre a prática educativo-progressiva em favor da autonomia do ser dos educandos é a temática central em torno de que gira este texto"(FREIRE, 2009, p.13).

\section{AMBIENTE HOSPITALAR: O COTIDIANO E AS NARRATIVAS DE SEUS ATORES}

O ambiente hospitalar do qual tratamos se configura como um local que oferta assistência social às pessoas que estão em tratamento médico-hospitalar na Fundação Santa Casa de Misericórdia do Pará.

A sua estrutura física é formada por enfermarias, corredores, refeitório, pátio, capela e jardim, onde existem brinquedos e árvores. Espaços nos quais se estabelecem as relações interpessoais entre os que se encontram em tratamento médico-hospitalar, seus familiares (acompanhantes) e os demais profissionais que atuam no hospital (enfermeiros, assistentes sociais, médicos, terapeutas ocupacionais, psicólogos, pedagogos e pessoal de apoio).

Dessa forma, cada sujeito participa da vida cotidiana em que se apresentam todos os aspectos de sua personalidade. A vida cotidiana é a vida do ser humano inteiro, com todas as suas capacidades, suas subjetividades, habilidades, ideologias. A vida cotidiana, em que o ser humano é inserido, tem como condição de organicidade o funcionamento da heterogeneidade e da ordem hierárquica que se modifica em função de estruturas econômicas e sociais (HELLER, 1989).

No cotidiano voltado para o tratamento de saúde, estabelecido neste ambiente hospitalar, as pessoas vão construindo suas significações sobre esse espaço que oferece as condições básicas de moradia, alimentação e higiene. Como expressa a educanda- paciente Rosa:

Pra mim assim, é um espaço que ele tá pronto a acolher as pessoas que vem do interior e eu acho que isso uma coisa boa que pra gente que vem do interior de longe. A gente não tem a donde morar então aqui eles acolhe a gente, tem a cama da gente, tem a refeição. Eles dão o material, negócio de banho, perfume então, é uma coisa muito boa pra nós que não tem condição de tá comprando o material.

Desta forma, são mães e filhas que trazem para o dia-a-dia suas marcas de um gênero que firma seus traços nas formas de representar-se em um cotidiano assinalado pelo sentimento de saudade da família e dos filhos distantes, pela busca da cura das enfermidades, e pela fé na vida. Como nos relata a educadora Carmem: 
Elas comungam da mesma dor, elas comungam da mesma vivência (...) porque as mães tem uma rotina muito grande dentro do hospital, é a mama, a comida das crianças. Tem aquelas que são diaristas, aquelas que tem as atividades delas de três em três horas tem a mama. Mães diaristas são aquelas que vão pro hospital de manhã cedo e ao final da tarde elas voltam pra casa. Tem a mãe coruja, que passa o dia inteiro lá, elas moram lá, as escalpeladas elas ficam albergadas no próprio Espaço Acolher.

Nesse espaço, a diferença se manifesta por meio das expressões culturais das pessoas que vêm de diversas localidades da região amazônica e trazem consigo os traços das suas formas de lidar com o tempo e com o espaço, sua linguagem e forma de pensar e agir diante do cotidiano de tratamento médico-hospitalar.

O tratamento de saúde gera toda uma desestrutura familiar, não são raros casos de educandaspacientes que são rejeitadas pelos seus companheiros. A ausência de saúde caracteriza um estigma, em que o isolamento, para as vítimas de escalpelamento, torna-se condição de vida. Assim, configura-se a complexidade saúde-doença-exclusão social, na qual se atribui à pessoa em tratamento de saúde uma condição de incapacidade ou anulação da sua participação nas práticas sociais cotidianas na família e na sua comunidade. Mostra como ainda é vigente a concepção de saúde, na qual a patologia torna-se principal referência de representação do outro pela sociedade.

Tal concepção de saúde coloca sob o indivíduo a responsabilidade por sua condição de vida, não sob o aspecto de sua autonomia enquanto sujeito de intervenção social, mas no sentido da sua adaptação ao meio ambiente e adequação às políticas prescritivas de saúde. A saúde é entendida de forma desligada dos fatores econômicos e sociais, cabendo ao ser humano a sua adaptação na sociedade. De modo que o não ajustamento à sociedade é que implicaria um estado de desequilíbrio, de doença (SILVA, 2001).

Assim, as condições de doença e estética do sujeito emergem como elementos de exclusão e negação social das diferenças. Dussel (1994) desconstrói o discurso ético hegemônico e socialmente excludente no qual a vítima (o Outro), o oprimido, diferente, torna-se culpada, a qual é objeto de diversos ataques violentos, cabendo ao sujeito hegemônico, opressor, o papel de civilizador, o inocente. Com o desenvolvimento de um contradiscurso ético-político-libertador, o autor apresenta a "Ética como critério de verdade prática e teórica, ou seja, a vida como condição de possibilidade para a ação e para a reflexão sobre a ação" (OLIVEIRA, 2005, p.104). Ética que nos possibilita a crítica aos processos legitimados socialmente de inferiorização do outro, a partir de referências de capacidade, estética, cultura, gênero, etnia, em um processo homogeneizador das formas de agir e pensar, formas de saber-ser.

No ambiente hospitalar, em meio aos horários de rotinas médicas, cada ambiente vai ganhando novos significados. As enfermarias e leitos se tornam quartos e camas, os internados na mesma enfermaria se tornam amigos de quarto e o que estão na enfermaria ao lado, vizinhos de quarto. É nesse contexto que 
a educanda Rosa indica que as pessoas em tratamento de saúde e seus acompanhantes "forma uma família". O refeitório não é apenas o local para alimentar-se, mas a sala onde se assiste televisão e, onde se estuda. $O$ pátio, local de visita, de ver movimento; o jardim local em que "as crianças brincam e se pega um ventinho" (ROSA). Em um espaço onde há uma imagem religiosa e um banco é a "Capelinha de Jesus". E, assim, aquele espaço estranho, alheio torna-se o lugar de cada um que faz parte dessa comunidade hospitalar.

A vida cotidiana é compreendida como essência da substância social e está inscrita historicamente. O ser humano nesse contexto é ativo e receptivo, é simultaneamente ser particular, pela sua unicidade e irrepetibilidade e genérico, como elemento que se apresenta em toda atividade expressão de suas relações sociais, herdeiro e preservador do desenvolvimento humano; mas o representante do humano-genérico não é jamais um indivíduo sozinho, mas sempre a integração (tribo, demos, estamento, classe, nação, humanidade)- bem como, frequentemente, várias integrações - cuja parte consciente é o homem em na qual se forma a sua "consciência de nós" (HELLER, 1989, p.21).

Com o desenvolvimento das atividades educativas do Núcleo no ambiente hospitalar, os encontros educativos passaram a fazer parte deste cotidiano e as educadoras também passaram a fazer parte desta comunidade.

\section{FORMAÇÃO DOCENTE POR MEIO DAS AÇÕES EDUCATIVAS DESENVOLVIDAS PELO NÚCLEO NO AMBIENTE HOSPITALAR}

O Núcleo desenvolve ações educativas de alfabetização e pós-alfabetização com crianças, jovens, adultos e idosos, provenientes das classes populares de Belém, das áreas periféricas e de municípios do Estado do Pará, objetivando o favorecimento da ampliação do conhecimento de educadores e educandos mediante experiências dialógicas de educação, centradas na valorização do ser humano, compreendido como sujeito da ação. “O atendimento educacional em ambiente hospitalar representa investimento na vida, expressa reconhecimento aos direitos de cidadania, direitos esses que precisam ser mantidos independentemente da condição de paciente" (COSTA; ROLIM, 2019, p.254).

Configura-se como agência de formação inicial e continuada de professores e estudantes dos cursos de licenciatura, dentre os quais, Matemática, Pedagogia, Ciências da Religião, bem como de especialistas, mestres e doutores que, no exercício de aprofundamento teórico-prático, oferecem contribuições para a academia científica por meio das produções resultantes de pesquisas que se materializaram na elaboração de artigos, trabalhos de conclusão de curso, monografias, dissertações e teses.

Atrelado às práticas de pesquisa, os grupos de estudo e trabalho possuem calendário de encontros de formação de professores dirigidos às especificidades metodológicas de cada comunidade atendida, produção do planejamento das aulas, avaliação e deliberação das estratégias de inserção comunitária. 
O Núcleo desenvolve ações de alfabetização e pós-alfabetização aos jovens, adultos e idosos em tratamento médico no Hospital Santa Casa de Misericórdia de Belém desde 2004. Os encontros educativos são marcados pela presença de mulheres que estão na faixa etária entre 14 e 60 anos. Em sua maioria são as mães adolescentes e as vítimas de escalpelamento, caracterizando uma especificidade aos encontros educativos que trazem na relação com o gênero toda uma dinâmica pedagógica na abordagem de temas que emergem dos interesses das educandas.

As ações educativas participativas desenvolvidas no ambiente hospitalar caracterizam-se pelo novo, constituindo-se em um grande desafio para os profissionais da educação, que diante das especificidades deste ambiente e de seu público exige a produção de novas metodologias de ensino, tendo em vista o cotidiano hospitalar.

A maioria dos educadores do Núcleo que são encaminhados para o trabalho no ambiente hospitalar ainda não tem experiência docente com as comunidades hospitalares e, ao aceitarem o desafio de desenvolver práticas educativas em espaços não convencionais de ensino, possibilitam-se a ressignificação do ambiente hospitalar e do ato educativo.

Eu imaginava assim, que quando eu entrei eu pensei o que será que vai acontecer? Qual será a reação dessas pessoas e de que forma essas pessoas que estavam lá eram pessoas em processo de alfabetização ou de pós- alfabetização? Eu imaginava que seria igual lá na escola, naquele ambiente que tem as cadeiras, o quadro a mesa, então quando você entra num espaço e vê que de início não tem nada do que tá esperando, então já entra num confronto com a mentalidade... Foi chocante, mas foi um chocante do bom né do lado bom, não do lado ruim (EDUCADORA CARINA).

McLaren (1991), com o seu estudo "A educação como um sistema cultural”, nos traz contribuições para a compreensão da educação em seu contexto cultural na construção de significados e símbolos materializados nas práticas cotidianas do cenário escolar, o qual é referência social como espaço de ensinar. Assim, quando se remete à prática educativa em locais não convencionais de ensino, tende-se a reproduzir os elementos que compõem a educação escolar, por meio de seus rituais e símbolos. Para o autor, "os rituais são inerentemente sociais e políticos; eles não podem ser entendidos isolados do modo como os indivíduos se situam biográfica e historicamente em várias tradições de mediação" (McLAREN, 1991, p.73).

Nos primeiros contatos com o cotidiano da comunidade hospitalar, as educadoras passaram por um momento de desconstrução das suas concepções sobre a prática educativa, tendo como referência a estrutura escolar, e organização do espaço físico da sala de aula, ao perceberem que os encontros educativos seriam realizados no refeitório e que o maior desafio de sua execução seria a adaptação a toda uma rotina voltada para o tratamento de saúde pelo qual as educandas (mães das crianças internadas e as vítimas de escalpelamento) passavam. 
Não sabia exatamente que tipo de público a gente ia atender, então, nós fizemos a pesquisa socioantropológica e mesmo sem saber esse público, nós tínhamos feito uma dinâmica de aproximação. Nós não sabíamos quem seriam os educandos, como seria essa relação. Era uma expectativa né tanto deles quanto nossa (...) por ser a primeira vez que a gente estava participando de um trabalho no ambiente hospitalar e de não saber o que eu ia encontrar, sabia que ia trabalhar com pacientes e seus acompanhantes, mas não sabia de onde eles vinham origem, a sua cultura e saber lidar (EDUCADORA CARMEM).

Dessa forma, as educadoras por meio de pesquisas, encontros formativos ofertados pelo Núcleo e planejamentos foram construindo as estratégias de superação das dificuldades de execução das aulas que iniciou com o trabalho de conquista das educandas, de estabelecimento de uma relação próxima, de confiança. Na medida em que para elas, viver uma experiência educativa, fora do ambiente escolar, em um momento tão complexo de tratamento de saúde, era visto como algo inacessível. Assim, o trabalho inicial das educadoras foi o de se aproximar do contexto de vida no hospital e tornar-se parte desse cotidiano, das relações interpessoais e dessa comunidade hospitalar.

Imersas no cotidiano do ambiente hospitalar as educadoras buscavam superar as dificuldades de encontrar um horário para o encontro educativo que fosse compatível com a disponibilidade das educandas, haja vista suas rotinas, no caso das mães, de acompanhamento dos filhos e das vítimas de escalpelamentos, de suas consultas e curativos. Outra dificuldade era a de encontrar as metodologias de ensino que se adequassem à fragilidade de saúde e emocional apresentadas pelas educandas, bem como a rotatividade que caracteriza as comunidades hospitalares.

A estratégia é sempre de fazer de cada encontro o encontro, o único porque devido sempre o nosso trabalho foi caracterizado pela rotatividade dentro dos espaços (...) a gente viu que não poderia fazer um planejamento fazendo essa seqüência de atividades, uma seqüencia da outra, embora a gente sempre tivesse fazendo a retomada. Agora a gente tem essa dificuldade, ter um planejamento que cada dia ele é o único, pra atingir o máximo possível os nossos objetivos, o planejamento é pensado a partir do que as mães mostram pra gente (EDUCADORA CARMEM).

Fazer com que a práxis educativa do Núcleo se tornasse parte do dia-a-dia do ambiente hospitalar não foi tarefa fácil, pois exigiu muita conviç̧ão das educadoras para pôr em prática o projeto de educação popular proposto, que teve no apoio da Assistência Social mais uma motivação para seguir.

Ir pra lá quase duas ou três semanas sem conseguir fazer nada, de não conseguir fazer as atividades, a gente teve que conquistar as mães pra estarem com a gente e ela (Assistente Social), sempre teve ali incentivando não! Não! Não! vão desistir ....vocês não vão desistir, vocês não vão sair daqui, não desanimem. Então as palavras dela sempre foram de muito incentivo do nosso trabalho (EDUCADORA CARMEM). 
Nesse processo, as educadoras foram cada vez mais se aproximando do contexto de vida diária destas mulheres, de seus dramas, suas aflições e encontraram os caminhos para desenvolver uma ação educativa que possibilitasse a problematização das situações limites às quais as educandas enfrentavam.

Candau (2020) destaca a importância do diálogo crítico no sentido de fortalecer perspectivas educativas e sociais orientadas visando os processos democráticos em todos os níveis e âmbitos, do macrossocial à sala de aula, cuja referência fundamental é o horizonte emancipador.

A cada encontro educativo foi sendo criada uma expectativa por parte das educandas-pacientes, na qual a presença deste projeto tornou-se essencial para a superação das dificuldades encontradas em contexto de tratamento médico hospitalar prolongado e fatigante. Dessa forma, as educadoras passaram a ser reconhecidas como integrantes da comunidade hospitalar, juntamente com as mães corujas, as escapeladas. As professoras passaram a ser reconhecidas como "as meninas": "As educadoras, as amigas, um pouquinho de psicólogas, as meninas, as professoras" (EDUCADORA CARMEM).

A presença da experiência educativa desenvolvida pelo Núcleo começou a gerar toda uma expectativa das educandas de aprender a ler e escrever, de ampliar o conhecimento, de dialogar e de superar com o outro os momentos de tensão e sofrimento, saudade, desesperança, evidenciados no dia-a-dia do ambiente hospitalar. Como indica a fala da educadora Carina: "sempre eles perguntam, a senhora vem amanhã? Não, a gente explica segunda, terça e quarta-feira, então eles sentem falta, ficam na expectativa".

A possibilidade para os educandos de aprender a ler e escrever em um ambiente hospitalar, em um momento doloroso de tratamento de saúde, se configura como prática de liberdade de escolha, superação do isolamento a socialização. De ressignificação da experiência educativa:

Não! Não, não, esperava até porque a gente não sabia, primeira vez que eu fui me internar e eu não sabia que tinha isso, pensei que era só internamento mesmo e tratamento pensei que não tinha esse momento, a pessoa largar o lar dele né? pra vim, é ter esse momento com a gente passar a experiência dele pra gente que tá aqui né no hospital doente, fazer essa amizade toda (ROSA).

A possibilidade de vivenciar uma experiência educativa no ambiente hospitalar apresenta-se como elemento significante na formação dos educadores:

profissionalmente significa um passo a mais como educadora, em atuar enquanto educador que pensa em espaço escolar e aprender ser professora em um ambiente hospitalar é diferente, a forma de educar é diferente, muito diferente da escola, então pra mim é um passo a mais, uma experiência a mais e pessoalmente é superar muitas coisas. Aprender a olhar o sujeito não a patologia dele naquele espaço, de não ter medo de estar lá, de ouvir (EDUCADORA CARMEM). 
Nesse contexto, a vivência educativa no ambiente hospitalar possibilita a seus atores, operar sobre suas subjetividades, projetando-se pra uma perspectiva presente e futura dinâmica e mutável. É um local onde, educandos e suas práticas sociais cotidianas ensinam o educador a educar (FREIRE,1993). Como prática de liberdade de sonhar: "sonhar não é apenas um ato político necessário, mas também uma conotação de forma histórico-social de estar sendo de mulheres e homens. Faz parte da natureza humana que, dentro da história se acha em permanente processo de tornar-se" (FREIRE, 1993, p.91).

Portanto, a formação docente, nessa perspectiva, encontra na humanização das relações com o saber, com o outro e com o mundo elementos de ruptura com as práticas tradicionais de ensino, em suas convenções e espaços tradicionalmente legitimados como únicos ambientes de ensinar e aprender.

\section{CONSIDERAÇÕES FINAIS}

Este artigo buscou favorecer ao leitor, adentrar no cotidiano do ambiente hospitalar, tendo como protagonismo as narrativas de seus atores, apontando os desafios da prática docente neste contexto comunitário, bem como a superação por meio da vivência formativa de educadores do Núcleo.

Os dados apontam que os pressupostos teóricos metodológicos Freireanos adotados pelo Núcleo: dialogicidade, oralidade, rigorosidade metódica e comprometimento ético-politico com as classes populares, funcionam como elementos fundamentais para a formação de professores de práxis inclusiva.

As complexidades saúde-doença-exclusão presentes no cotidiano educativo do ambiente hospitalar exigem a formação docente humanizadora e crítica-reflexiva, para a superação das condições de opressão frente ao tratamento de saúde prolongado e doloroso, para a viabilização da relação educação-inclusão social.

As educadoras do Núcleo indicam que a prática da educação popular em ambiente hospitalar se configura como um constante desafio, como superação e encantamento e, no concretizar dessa experiência, a formação dos sujeitos envolvidos revela-se na abertura às novas possibilidades e formas de estar no mundo enquanto educando, educador, acadêmico, profissional, membro de uma família, de uma comunidade, mas, principalmente, enquanto ser humano.

De modo que os dados apontam que o Núcleo se materializa como agência formadora, como espaço de fomentação de aprendizagens. Segundo o relato das educadoras participantes da pesquisa, como espaço que possibilita a compreensão teórica e prática da educação popular e a percepção dos seus atores como sujeitos e não como objetos na práxis de uma educação para a autonomia.

Como forma de desmistificar a concepção de ambiente hospitalar como espaço de isolamento social e de negação das subjetividades humanas, espaço de ociosidade e sofrimento, a educação popular em ambiente hospitalar demonstra que nesse espaço e no contexto de tratamento de saúde se estabelecem 
redes de saberes, símbolos, crenças, aprendizagens, manifestações humanas que perpassam pelas expressões culturais e políticas do contexto de vida de cada ser humano. Buscando romper com o caráter meramente informativo, tal proposta educativa parte do princípio da compreensão do ser humano em sua totalidade e complexidade, na construção dos saberes e práticas cotidianas e nas relações interpessoais de expressão cultural, de subjetividades e conflitos.

Nesse contexto, a educação popular defende a emergência de ações educativas que tem como premissa a valorização dos sujeitos em suas diferenças, sob a ótica da valorização do outro enquanto ser singular e cultural e não sob a perspectiva de um modelo de ser humano construído ideologicamente por uma cultura dominante. Trata-se de uma ação educativa para a alteridade, que, como inclusiva, rompe com o olhar determinista sobre o ser humano.

Nessa perspectiva, as dimensões do cotidiano: sociais, físicas-biológicas, culturais, subjetivas e políticas se interligam na relação com o saber, com as vivências educacionais compondo um indispensável aspecto da formação de professores em seus saberes de experiência, adquiridos no cotidiano, e da experiência, adquiridos na prática docente. Condições que contribuem para a formação de professores conscientes de seu estar sendo, especialmente na sua condição de favorecer a transformação social de realidades excludentes.

\section{REFERÊNCIAS}

BRANDÃO, Carlos. A Educação como Cultura. Campinas: São Paulo: Mercado das letras, 2002.

CANDAU, Vera Maria. Didática, Interculturalidade e Formação de professores: desafios atuais. Revista Cocar. Edição Especial. N.8. Jan./Abr. 2020. Disponível em: https://paginas.uepa.br/seer/index.php/cocar/article/view/3045/1329. Acesso em: 08 de abril de 2020.

COSTA, Jaqueline Mendes; ROLIM, Carmem Lúcia Artioli. Classe Hospitalar na Região Norte do Brasil: construção de Direito. Revista Tempos e Espaços em Educação, v.12, n.29, p.247-262, abri./Jun. 2019. Disponível em: https://seer.ufs.br/index.php/revtee/article/view/9041/pdf. Acesso em: 15/02/2020.

DUSSEL, Enrique. Crítica del "mito de la modernidad" e Dos paradigmas de la Modernidad. In: EI encubrimiento del Índio: 11492: hacia el origen del mito de la modernidad. México: Cambio XXI; Colégio Nacional de Ciências Políticas y Administración Pública, 1994.

FLEURI, Reinaldo. Políticas da diferença: para além dos estereótipos na pratica educacional. In: Educação \& Sociedade. № 95 Vol, 27. Maio/ Ago. 2006. Disponível em: http://www.cedes.unicamp.br. Acesso em: 20/02/2020.

FREIRE, Paulo. Pedagogia do oprimido. Rio de Janeiro, Paz e Terra, 1987. 
FREIRE, Paulo. Pedagogia da autonomia: saberes necessários à prática educativa. São Paulo, Paz e Terra, 1996.

GAZZINELLI, Maria. Educação em saúde: teoria, método e imaginação. Belo Horizonte: Ed. UFMG, 2006.

HAGUETTE, Teresa. Metodologias qualitativas na sociologia. Petrópolis: Vozes, 1987.

HELLER, Agnes. O cotidiano e a história. 3. ed. Rio de Janeiro: Paz e Terra, 1989.

LAKATOS, Eva, MARCONI, Maria. Técnicas de pesquisa. São Paulo: Atlas, 2007.

MACLAREN, Peter. Multiculturalismo Crítico. In: Multiculturalismo e a crítica pósmoderna: por uma pedagogia da resistência e transformação. São Paulo: Cortez, 1997.

MAFFESOLI, Michel. A vivência. Elogio da razão sensível. Petrópolis: RJ:Vozes,1998

MINAYO, Maria. O desafio do conhecimento: pesquisa qualitativa em saúde. 6 ed.São Paulo: Hucitec; Rio de Janeiro: Abrasco, 1999.

NEP-UEPA . Projeto Educação Popular em Ambiente Hospitalar: processo de inclusão social e educacional. 2008

OLIVEIRA. Ivanilde. Filosofia da educação: reflexões e debates. Belém: UNAMA, 2001.

OLIVEIRA, Ivanilde. Princípios pedagógicos na educação de jovens e adultos. Revista da Alfabetização Solidária, v.4, n.4, São Paulo: Unimarco, 2004.

OLIVEIRA, Ivanilde e XAVIER, Mário (Orgs.). Palavra-ação em Educação de Jovens e Adultos. Belém: CCSE-UEPA, 2002.

PENIN, Sônia. Cotidiano e escola: a obra em construção. São Paulo: Cortez, 1989.

RIBEIRO, Natalia. Necessidade e dilemas das famílias das vítimas de escalpelamento atendidas na Fundação Santa Casa de Misericórdia do Pará: Desafios para o Serviço Social. Trabalho de Conclusão de Curso, graduação em Serviço Social- UFPA, Belém, 2009.

SILVA, Jacqueline. Educação e saúde: palavras e atos. Porto Alegre: Dacasa Editora, 2001

SOARES, Marta Genu; MOREIRA, Laine Rocha; BENTES, José Anchieta de Oliveira. A Filosofia Relacional Dialógica e as Perspectivas do Interculturalismo na Educação. Revista Tempos e Espaços em Educação. v. 12, n. 30, p.275-290. Jul./Set. 2019. Disponível em: https://seer.ufs.br/index.php/revtee/article/view/11124/pdf. Acesso em 10/02/2020.

TARDIF, Maurice. Saberes docentes e formação profissional. Petrópolis: Vozes, 2004.

TARDIF, Maurice; GAUTHIER, Clermont. O saber profissional dos professores - fundamentos e epistemologia. In: Seminário de pesquisa sobre o saber docente, 1996, Fortaleza. Anais. Fortaleza: UFCE, 1996. 


\section{SOBRE O(A/S) AUTOR(A/S)}

\section{Wany Marcele Costa Góes Dias}

Mestre em Educação pela UEPA- Graduada em Pedagogia pela UEPA. Professora da rede municipal de ensino de Belém- SEMEC. Especialista em Educação- SEDUC e Pesquisadora do Núcleo de Educação Popular Paulo Freire da Universidade do Estado do Pará.

E-mail: wanymarcele@hotmail.com

Orcid: https://Orcid.org/0000-0002-4747-3126

\section{Ivanilde Apoluceno de Oliveira}

Pós-doutora em Educação pela PUC-RIO. Doutora em Educação pela PUC-SP. Graduada em Filosofia pela UFPA. Professora e pesquisadora do Programa de Pós-Graduação em Educação e Coordenadora do Núcleo de Educação Popular Paulo Freire da Universidade do Estado do Pará.

E-mail: nildeapoluceno@uol.com.br

Orcid: https://orcid.org/0000-0002-3458-584X

Recebido em: $10 / 03 / 2020$

Aprovado em: 01/05/2020

Publicado em: $12 / 05 / 2020$ 